\title{
Ecological dissonance in decision-making participation systems as a predictor of job satisfaction, involvement, alienation, and formalization
}

\author{
DUANE I. MILLER, SHAHUREN ISMAIL, J. MARTIN GIESEN, \\ and CAROLYN ADAMS-PRICE \\ Mississippi State University, Mississippi State, Mississippi \\ and \\ JEFF S. TOPPING \\ San Joaquin Delta College, Stockton, California
}

\begin{abstract}
The discrepancy between measures of preferred and actual participation in decision making was used as a measure of ecological dissonance for an organization and then used to assess its relationship to job satisfaction, job involvement, job alienation, and job formalization. Questionnaires were administered to 143 faculty and staff members of Mississippi State University. Correlational analyses indicated mild relationships between the measures of ecological dissonance and job satisfaction, job involvement, job alienation, and job formalization, thus providing support for ecological dissonance theory (see Miller, Topping, \& Wells-Parker, 1989). It was concluded that ecological dissonance in participation in decision making was a predictor of workers' job satisfaction, job involvement, job alienation, and job formalization.
\end{abstract}

Based on Festinger's (1957) cognitive dissonance theory and Barker's (1968) ecological theory, ecological dissonance theory (see D. I. Miller, Topping, \& Wells-Parker, 1989) was developed to explain the motivational dynamics that result when environmental systems or environmental and cognitive systems come into conflict. An example of this type of conflict occurs when a law, such as an antidiscrimination law, comes into conflict with the norms of a given culture. Ecological dissonance theory proposes that this conflict energizes forces directed at the reduction of the ecological tension being generated by the conflict; energy expended in dealing with the conflict is a function of the amount of dissonance in the ecological systems, which in turn is a function of the proximity and power of the systems in conflict. Ecological dissonance can be reduced by mechanisms such as bargaining, mediation, legal adjudication, and increased formalization; until removal of the tension is accomplished, there will be pressure on the individuals of the ecologically imbalanced system. Finally, this pressure will be manifested in several ways, including low worker morale (D. I. Miller et al., 1989).

Recently, several studies have examined ecological dissonance theory (D. I. Miller, Burton, Giesen, Topping, \& Reagan, 1990; D. I. Miller et al., 1992; D. I. Miller, Majors, Giesen, \& Topping, 1990; D. I. Miller \& Top-

Correspondence should be addressed to D. I. Miller, P.O. Box 6161, Mississippi State University, Mississippi State, MS 39762-6161. ping, 1991), and such research has provided weak but statistically significant support for the theory.

The purpose of the present study was to examine the relationship between a new measure of ecological dissonance and the criteria of work morale and work formalization. The ecological dissonance measure was constructed by using the Measure of Centralization developed by Aiken and Hage (1968), cited in Price (1972). An index of ecological dissonance was created by determining the discrepancy between the perceived level of participation and the desired level of participation. These discrepancy scores were correlated with measures of job satisfaction, job involvement, job alienation, and job formalization. As deduced from the theory, negative correlations were predicted between the discrepancy scores and job satisfaction and job involvement, and positive correlations were predicted when correlating the discrepancy scores with job alienation and job formalization.

\section{METHOD}

\section{Subjects}

The subjects were 143 faculty and staff members in various departments at Mississippi State University. The names of the subjects were selected at random by using the 1991/1992 Mississippi State University faculty, staff, and student telephone directory. No incentive was offered to the subjects.

\section{Procedure and Materials}

The survey consisted of two parts. The first part was made up of 18 items from the Index of Participation in Decision Making developed from Aiken and Hage's (1968; Price, 1972) Measure of Centralization. The second 
part consisted of (1) 15 items from Hage and Aiken's (1969) Measure of Formalization and (2) the Index of Work Morale, which includes 18 items from Brayfield and Rother's (1951) Index of Job Satisfaction, 5 items from G. A. Miller's (1967) Index of Alienation, and 6 items from Lodahl and Kejner's (1965) Index of Job Involvement. Eight demographic items were also included at the end of the questionnaire.

Aiken and Hage's (1968) Measure of Centralization was divided into two measures. The first measure was the Index of Participation in Decision Making, which indicates how much the respondent participates in decisions about the allocation of resources and the determination of organizational policies. The second measure was the Index of Hierarchy of Authority, which refers to decisions involving the immediate work and indicates the degree of reliance on the hierarchy of authority in making work decisions at the immediate workplace.

The questionnaire was modified to measure each respondent's preferences for participation in decision making and actual participation. In the Index of Participation in Decision Making and the Index of Hierarchy of Authority, the respondents were asked to indicate the frequency of their preferred and actual participation in decision making. The difference between preferred and actual participation was the measure of ecological dissonance.

In the Index of Job Satisfaction, satisfaction is defined as how people feel about their jobs (Price, 1972). For this measurement, the respondents were asked to respond to statements pertaining to their jobs. In the Index of Job Involvement, job involvement is defined as the degree to which a person's work performance affects his/her self-esteem (Lodah \& Kejner, 1965). For the Index of Job Alienation, alienation is defined as the degree of dependence of the given behavior upon rewards that lie outside the activity itself (G. A. Miller, 1967).

Formalization is referred to as the importance of rules in an organization (Hage \& Aiken, 1969). The Measure of Formalization is made up of five different types of measurement: job codification, rule observation, rule manual, job description, and the specificity of job description.

The questionnaires, with a cover letter, were mailed to 300 faculty and staff members of Mississippi State University. The subjects were asked to respond to the survey by following the instructions provided for each part of the questionnaire and to return the completed survey using the enclosed self-addressed stamped envelope.

\section{RESULTS AND DISCUSSION}

Pearson product-moment correlation coefficients were calculated to see if there were any significant relationships between the measures of ecological dissonance at the two decision-making levels (organizational and work decision levels) and the Indexes of Job Satisfaction, Job Involvement, and Alienation and the Measure of Formalization.

There were significant negative correlations between the respondents' Index of Job Satisfaction and the ecological dissonance scores for all the types of organizational decision making. The correlation coefficients yielded were $r(135)=-.29, p<.01$, for decisions on the hiring of personnel; $r(135)=-.23, p<.01$, for decisions on the adoption of new policies; $r(135)=-.25, p<.01$, for decisions on the institution of new services; and $r(135)$ $=-.31, p<.001$, for total organizational decisions. Therefore, the significant negative correlations suggested that the respondents who perceived ecological dissonance in organizational decisions appeared to be dissatisfied with their jobs.

Significant negative correlations were also obtained for the relationships between the Index of Job Involvement and the ecological dissonance scores at the organizational decision-making level: $r(135)=-.17, p<.05$, for decisions on the hiring of personnel, and $r(135)=-.16, p<$ .05 , for total organizational decisions. Very weak relationships, but in the predicted negative direction, were observed between the Index of Job Involvement and the ecological dissonance scores in organizational decisions concerning promotion of personnel, adoption of new policies, and institution of new services. The significant negative correlations suggested that the respondents who perceived ecological dissonance in organizational decision making regarding the hiring of personnel and the total organizational decisions were not involved or were less involved in their jobs.

Significant positive correlations were observed between the Index of Alienation and the ecological dissonance scores at the organizational decision-making levels: $r(137)$ $=.14, p<.05$, for decisions on the institution of new services, and $r(137)=.16, p<.05$, for total organizational decisions. Very weak relationships, but in the predicted positive direction, were observed between the Index of Alienation and the ecological dissonance scores in the organizational decisions regarding the hiring and promotion of personnel. The significant positive correlations suggested that the respondents who perceived ecological dissonance in making organizational decisions concerning the adoption of new policies, the institution of new services, and the total organizational decisions were more likely to feel alienated in their jobs.

A significant negative relationship was observed between ecological dissonance scores at the work decision level and the Index of Job Satisfaction $[r(132)=-.16$, $p<.05]$. No other significant relationships were observed between ecological dissonance scores at the work decision level and the Indexes of Job Involvement and Alienation, although the correlations were in the predicted direction.

Significant positive correlations were obtained for the relationships between the measure of job codification and the ecological dissonance scores at all of the types of organizational decisions: $r(141)=.21, p<.01$, for decisions on the promotion of personnel; $r(141)=.25, p<$ .01 , for decisions on the instituting of new services; and $r(141)=.29, p<.001$, for total organizational decisions. The significant positive correlations suggested that the respondents who perceived ecological dissonance in all of the types of organizational decisions also perceived job formalization in the form of job codification.

Significant positive correlations were also obtained for the relationships between the measure of rule observation and the ecological dissonance scores in organizational decision-making levels: $r(141)=.17, p<.05$, for decisions about hiring of personnel; $r(141)=.24, p<.01$, for decisions on the promotion of personnel; $r(141)=$ $.23, p<.01$, for decisions on adopting new policies; $r(141)=.24, p<.01$, for decisions on instituting new services; and $r(141)=.27, p<.01$, for the total organizational decisions. The significant positive correlations 
suggested that respondents who perceived ecological dissonance in all the types of organizational decisions also perceived job formalization in the form of rule observation.

Very weak correlations were observed between the ecological dissonance scores in all the types of organizational decisions and the other measures of formalization (i.e., the measures of rule manual, job description, and specificity of job description).

A highly significant positive correlation was obtained for the relationship between the ecological dissonance score at the work decision-making level and the measure of job codification $[r(138)=.46, p<.001]$. A significant positive correlation was also obtained for the relationship between the ecological dissonance score at the work decision-making level and the measure of rule observation $[r(138)=.34, p<.001]$.

The significant correlations suggested that the respondents who perceived ecological dissonance at the work decision level would also experience job formalization in the form of job codification and rule observation. Very weak correlations were obtained for the relationships between the ecological dissonance at the work decision level and the other measures of formalization (i.e., the measures of rule manual, job description, and specificity of job description).

The present results indicated support for the hypothesis that the respondents who had experienced ecological dissonance, as measured by the discrepancy in the measures of participation in decision making, also experienced alienation, noninvolvement, and dissatisfaction in their jobs. The ecological dissonance generated at the organizational decision-making level was significantly related to the participants' job satisfaction, job involvement, and job alienation. Similar results were also reported by other researchers where ecological dissonance showed a significant relationship with satisfaction, involvement, and alienation (D. I. Miller, Burton et al., 1990; D. I. Miller et al., 1992; D. I. Miller, Majors et al., 1990; D. I. Miller \& Topping, 1991). Ecological dissonance at the organizational decision-making level was found to be a good predictor of the participants' job satisfaction, job involvement, and job alienation.

Discrepancy in the measure of participation in decision making at the work decision level indicated ecological dissonance, but it was significantly related only to the participants' job satisfaction. No significant relationship was observed with job involvement or job alienation, but the correlation coefficients indicated that ecological dissonance at the work decision level was related to the participants' job involvement and job alienation in the predicted direction.

The significant relationships between the ecological dissonance scores (at both the organizational and work decision levels) and the measures of formalization provided support for the hypothesis that the respondents who had experienced ecological dissonance would also indicate that they had experienced job formalization. These significant relationships, as observed between the ecological dissonance scores in all the types of decision making and the measures of job codification and rule observation, were what would be expected from the fourth proposition of D. I. Miller et al.'s (1989) ecological dissonance theory, which predicts increased formalization of interaction in ecologically dissonant climates. Thus, the present study showed that ecological dissonance was related to formalization of interaction, specifically job codification and rule observation. However, there is no way to tell if ecological dissonance caused the formalization of interaction. It is possible that formalization caused ecological dissonance, or both variables might have been controlled by a third factor.

In conclusion, the results of the present study support the hypotheses that discrepancies in decision-making participation measures can be a useful indicator of ecological dissonance and a predictor of job satisfaction, job involvement, job alienation, and job formalization.

\section{REFERENCES}

Aiken, M., \& Hage, J. (1968). Organizational interdependence and intra-organization structure. American Sociological Review, 33, 912-930.

BARKER, R. (1968). Ecological psychology. Stanford: Stanford University Press.

Brayfield, A. H., \& Rother, H. F. (1951). An index of job satisfaction. Journal of Applied Psychology, 35, 307-311.

FESTINGER, L. (1957). A theory of cognitive dissonance. New York: Row-Peterson.

HAGE, J., \& AIKEN, M. (1969). Routine technology, social structure, and organizational goals. Administrative Science Quarterly, 14, 366-376.

LODAhl, T. M., \& KejNer, M. (1965). The definition and measurement of job involvement. Journal of Applied Psychology, 49, 24-33.

Miller, D. I., Burton, B., Giesen, J. M., Topping, J. S., \& ReAGAN, C. (1990). Ecological dissonance theory and criterion validity of the Hooper equal opportunity measure. Psychology Reports, 66, 1155-1158.

Miller, D. I., Lin, S., Giesen, J. M., McMillen, D. L., WellsParker, E., SAnderson, P., \& Topping, J. S. (1992). Leadership power discrepancies and worker morale: A test of ecological dissonance theory. Bulletin of the Psychonomic Society, 30, 221-222.

Miller, D. I., Majors, M., Giesen, M., \& Topping, J. S. (1990). The Hooper equal opportunity measure: An operational definition of ecological dissonance theory. Bulletin of the Psychonomic Society, 28, 164-166.

Miller, D. I., \& ToPPING, J. S. (1991). Factors of ability, communication, grievances, and personal optimism as predictors of student satisfaction, involvement, and alienation: An ecological dissonance interpretation. Bulletin of the Psychonomic Society, 29, 19-20.

Miller, D. I., TopPing, J. S., \& Wells-Parker, E. N. (1989). Ecological dissonance and organizational climate. Psychological Reports, 32, 163-166.

Miller, G. A. (1967). Professionals in bureaucracy: Alienation among industrial scientists and engineers. American Sociological Review, 32, 755-768.

PrICE, J. L. (1972). Handbook of organizational measurement. Lexington, MA: Heath.

(Manuscript received October 27, 1992.) 